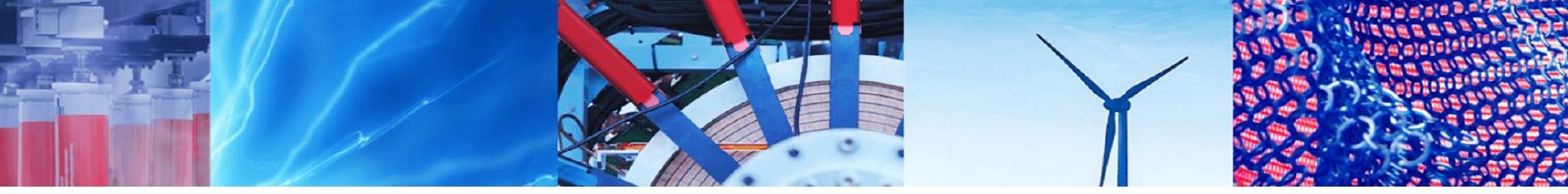

Research Article

\title{
Compression behavior of natural graphite sheet
}

\author{
Martin Cermak $^{1}$ (I) Majid Bahrami ${ }^{1}$
}

Received: 3 January 2020 / Accepted: 21 January 2020 / Published online: 6 February 2020

(c) Springer Nature Switzerland AG 2020

\begin{abstract}
The compression behavior of natural graphite sheet (NGS) is studied during the forming process and during the compression of finished sheets. The forming process, in which the low-density semi-finished NGS is compressed to higher densities, is quantified by the proposed relationship $p_{f}=0.35 e^{2.6 d}$ where $d$ is the free-standing density in $\mathrm{g} \mathrm{cm}^{-3}$ and $p_{f}$ is the forming pressure in MPa. The maximum achievable free-standing density is in the range $1.73-1.89 \mathrm{~g} \mathrm{~cm}^{-3}$. The compression behavior of finished NGS is non-linear, hysteretic, and density-dependent with the maximum strain of $6 \%$ at $0.55 \mathrm{~g} \mathrm{~cm}^{-3}$. The tangent compression modulus increases with the density and ranges from 20 to $220 \mathrm{MPa}$. A compact relationship for evaluating the strain at a given pressure and density is provided. NGS deforms viscously during the periods of constant pressure; the deformation is significant during the forming process but small during the compression of finished sheets.
\end{abstract}

Keywords Natural graphite sheet · Flexible graphite $\cdot$ Compressed exfoliated natural flake graphite $\cdot$ Forming $\cdot$ Uniaxial compression · Tangent modulus · Viscoelastic behavior $\cdot$ Barreling

\section{List of symbols}

$\epsilon_{v} \quad$ Viscous strain

$d \quad$ Density

$p \quad$ Pressure

$p_{f} \quad$ Forming pressure

$t_{f} \quad$ Thickness after the forming cycle

$t_{n} \quad$ Thickness after the $\mathrm{n}$-th cycle

$t_{v, 0} \quad$ Thickness at the beginning of the constant pressure period

$t_{v, \text { end }}$ Thickness at the end of the constant pressure period

\section{Introduction}

Natural graphite sheet (NGS) is a porous, anisotropic, and compressible material, which is also known as flexible graphite, graphite foil, or compressed exfoliated natural graphite. Historically, it has been used for sealing gaskets for its ability to conform to rough surfaces, withstand high temperatures, and resist corrosive fluids. Recently, NGS is used-or being considered to be used-in multiple sustainable energy technologies such as fuel cells [1-3], flow batteries $[4,5]$, adsorption cooling systems [6], heat exchangers [7] and light-weight heat sinks [8,9].

NGS is formed by compressing exfoliated natural graphite flake particles (worms) without using a binder [10]; the higher is the forming pressure the higher is the density of the final NGS. While the forming process is irreversible and results in permanent thickness reduction, the compression of finished NGS at pressures lower than the forming pressure is an elastic process [11].

An in-depth understanding of the forming process is crucial for preparing samples for material characterization, as well as for designing and optimizing the manufacturing process of NGS components and systems. The relationship between the forming pressure $p_{f}$ and free-standing density has been studied by Wang et al. [12], Dowell and Howard [11], and Wei et al. [13]; however, none of the studies covers the entire range of densities and the values by Wei

Majid Bahrami, mbahrami@sfu.ca| ${ }^{1}$ Laboratory for Alternative Energy Conversion, School of Mechatronic Systems Engineering, Faculty of Applied Science, Simon Fraser University, 250-13450 102 Avenue, Surrey, BC V3T OA3, Canada. 
et al. [13] do not agree with the other studies. The maximum achievable free-standing density was reported to be in the range from $1.73 \mathrm{~g} \mathrm{~cm}^{-3}$ [11] to $1.89 \mathrm{~g} \mathrm{~cm}^{-3}$ [13]. The conclusions about whether the trapped air in the pores affects the compression behavior vary [11, 14], and despite the fact that NGS was shown to have a viscoelastic behavior [15], the implications on the forming process have not been investigated. A strong viscous contribution would mean that the forming pressure is not the only parameter and the dwell time would have to be considered too.

A detailed quantitative description of the compression behavior of finished NGS in the form of stress-strain curves is important for measuring the material properties under compression, as well as for analyzing the behavior of NGS parts in engineering products. For example, predicting the thermomechanical stresses in fuel cell stacks is only possible when the coefficient of thermal expansion (CTE) and stress-strain data are available [16]. The literature coverage is limited with only sparse stress-strain data points reported by Luo and Chung [17] and elastic modulus values by Afanasov et al. [18]. The effect of density on the compression behavior has not been thoroughly studied.

The goals of this study are to (1) characterize the forming process in which a single semi-finished low-density sheet is compressed into the desired density ranging from 0.5 to $1.7 \mathrm{~g} \mathrm{~cm}^{-3}$; (2) quantify the compression behavior of finished NGS sheets at pressures up to $1 \mathrm{MPa}$; and (3) investigate the potential viscoelastic behavior of NGS under compression.

\section{Experimental method}

The measurements were conducted using a Bose Electroforce 3300 Series II machine (Fig. 1a) whose test section (Fig. 1b) consists of two circular compression platens 50 $\mathrm{mm}$ in diameter. The top moving platen is connected to the force actuator and the displacement sensor, while the bottom fixed one is connected to the load cell. The details of the measurement including the images of samples and uncertainty analysis are described in [19]. The raw data files and Matlab implementation of the data processing method are available in [20].

All samples were prepared from a low-density $\left(0.2 \mathrm{~g} \mathrm{~cm}^{-3}\right)$ semi-finished graphite sheet supplied by Nano Carbon Technology CO., LTD, Qingdao, China with the claimed properties stating the fixed carbon content $99.27 \%$, exfoliation volume $250 \mathrm{ml} \mathrm{g}^{-1}$, and the flake size composition of $81 \%$ larger than $300 \mu \mathrm{m}$ (50 mesh).

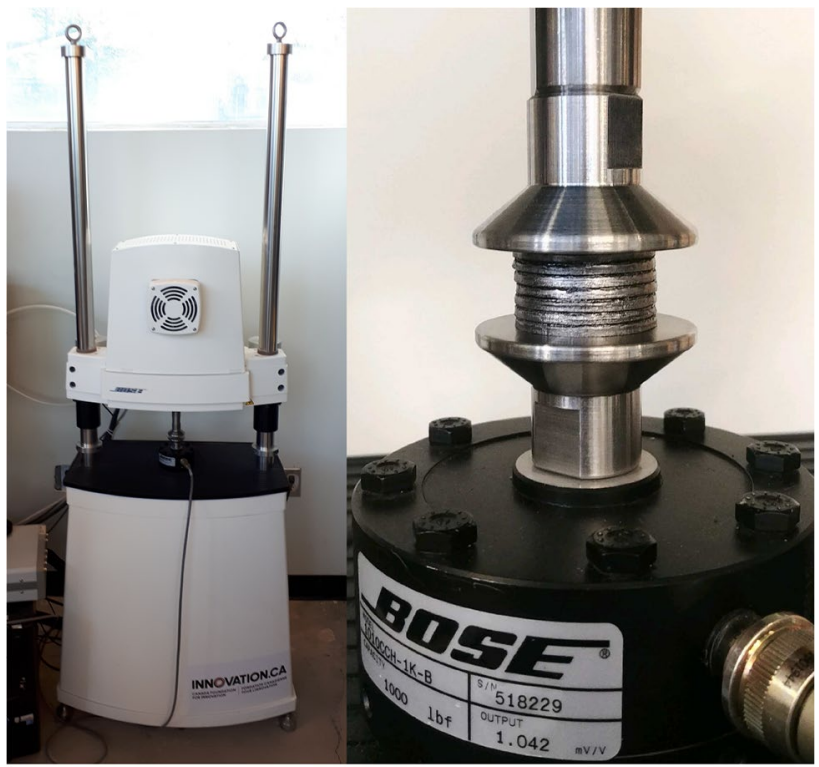

(a)

(b)

Fig. 1 a A photograph of the Bose Electroforce 3300 Series II machine used for the measurements, $\mathbf{b}$ a detailed image of the test section with compression platens

For the forming tests, the samples were cut from the low-density sheet using a metal hand saw into squares 10 $\mathrm{mm}$ to $15 \mathrm{~mm}$ wide. The size was chosen so that the desired pressure can be achieved given the maximum actuator force limit of $2100 \mathrm{~N}$ the used equipment. The measurement consisted of loading the samples to the given value of forming pressure $p_{f}$ at the rate of $30 \mathrm{kPas}^{-1}$, holding for $10 \mathrm{~s}$, and unloading at the same rate.

The samples of finished NGS were prepared in two steps. First, the semi-finished sheet was calendered between two $93.5 \mathrm{~mm}$ cylinders into four sets of sheets $2.76 \mathrm{~mm}, 1.43 \mathrm{~mm}, 0.96 \mathrm{~mm}, 0.84$ $\mathrm{mm}$, thick, which corresponds to the densities of $0.55 \mathrm{~g} \mathrm{~cm}^{-3}, 1.05 \mathrm{~g} \mathrm{~cm}^{-3}, 1.54 \mathrm{~g} \mathrm{~cm}^{-3}$, and $1.7 \mathrm{~g} \mathrm{~cm}^{-3}$, respectively. In the second step, discs $32 \mathrm{~mm}$ in diameter were cut from the calendered sheets using a hole punch. During the measurement, stacking of multiple samples was necessary because the dimension change of a single sheet at $1 \mathrm{MPa}$ is in the order of the uncertainty of the displacement measurement. A single measurement consisted of compression to $1.06 \mathrm{MPa}$ at the rate of $1.58 \mathrm{kPas}^{-1}, 10$-s hold, and decompression at the same rate. At least six measurements, in which the number of sheets in the stack was varied, were performed for each of the four studied densities. After each of the measurements, the samples were dismounted and a different combination of all available samples was measured next. 


\section{Results}

\subsection{Forming}

The relationship between the free-standing density after a single compression cycle to the forming pressure $p_{f}$ is shown in Fig. 2. The present data is in a good agreement with Wang et al. [6] showing the maximum relative difference of $20 \%$ at $1.25 \mathrm{gcm}^{-3}$. The single data point at the high forming pressure of $31 \mathrm{MPa}$ reported by Dowell and Howard [11] follows the exponential trend seen at low pressures. The pressure required to compress the sheet to the desired density follows the proposed relationship:

$p_{f}=0.35 e^{2.6 d}$,

where $d$ is density in $\mathrm{gcm}^{-3}$ and $p_{f}$ is the forming pressure in $\mathrm{MPa}$.

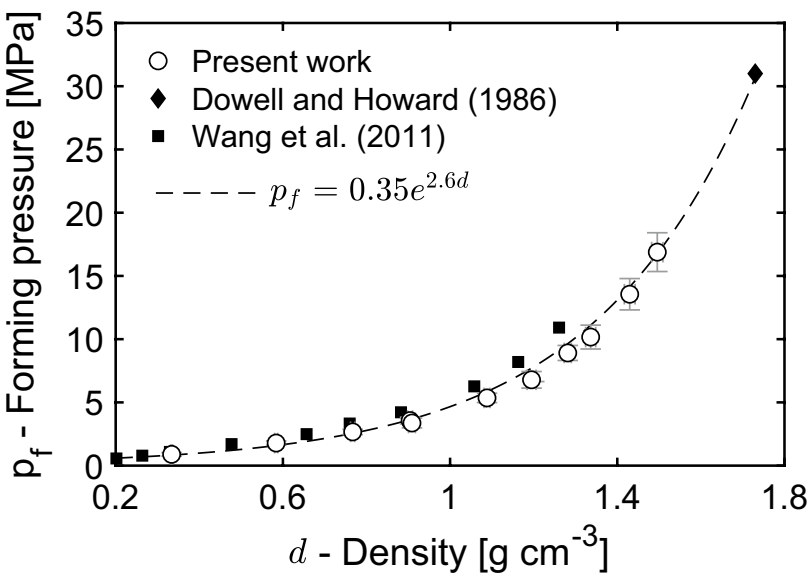

Fig. 2 The free-standing density as a function of the forming pressure. The curve fit $p_{f}=0.35 e^{2.6 d}$ was based on all the data points including the literature sources
A viscous behavior was observed during the periods of constant pressure at the peaks of the compression cycles as shown in Fig. 3a where the thickness is seen to decreases exponentially. The change in the thickness was quantified using the viscous strain $\epsilon_{v}$ which is defined as:

$\epsilon_{v}=\frac{t_{v, \text { end }}-t_{v, 0}}{t_{v, 0}}$

where $t_{v, 0}$ and $t_{v, \text { end }}$ are the thicknesses at the beginning and end of the constant pressure period, respectively. In Fig. $3 \mathrm{~b}$ the viscous strain $\epsilon_{v}$ is plotted against the forming pressure and a decreasing trend of the magnitude can be seen. At low forming pressures $p_{f}<2 \mathrm{MPa}$, which correspond to the free-standing densities up to $0.7 \mathrm{~g} \mathrm{~cm}^{-3}$, the thickness of the sheet reduces by $2-3 \%$. At higher pressures, $\epsilon_{v}$ becomes negligible and the dimension change is within the uncertainty of the measurement.

Re-loading the samples to pressures up to $75 \%$ of the forming pressure does not affect the final density. Repeated loading to the forming pressure increases the sheet density but after 24 cycles the increase becomes insignificant and the overall density increase is $4 \%$. The detailed results of the measurements can be found in [19].

\subsection{Compression of finished NGS}

The stress-strain curves for each of the measured densities are compiled in Fig. 4. To improve the clarity of the figure, only the maximum and minimum measurements are shown. For all densities, the results show a hysteretic behavior that is most pronounced for the lowest density sample $\left(0.55 \mathrm{~g} \mathrm{~cm}^{-3}\right)$ and decreases with increasing density. The shape of the stress-strain curves and the value of the maximum strain varies with density. The lowest measured density $\left(0.55 \mathrm{~g} \mathrm{~cm}^{-3}\right)$ shows almost linear behavior during the compression but the decompression is highly
Fig. 3 a lllustration of the viscous behavior at constant pressure, $\mathbf{b}$ viscous strain as a function of the forming pressure (a)

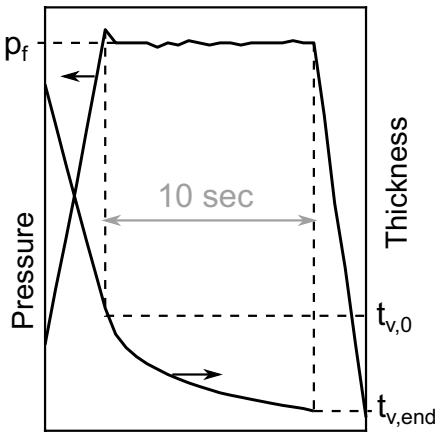

Time (b)

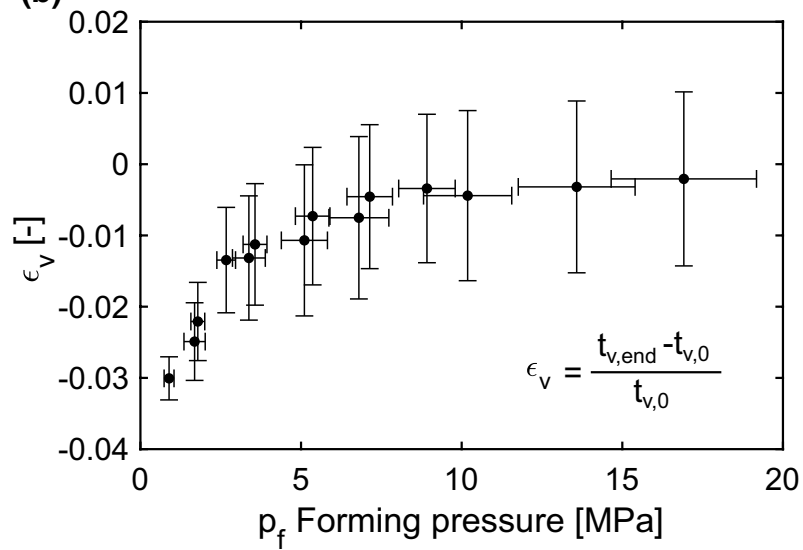


Fig. 4 Stress-strain curves of finished NGS. Loading and unloading is represented by the solid and dashed lines, respectively. For each of the plots only two measurements with maximum and minimum value of strain are shown to demonstrate the measurement variability. The grey area represents the measurement uncertainty

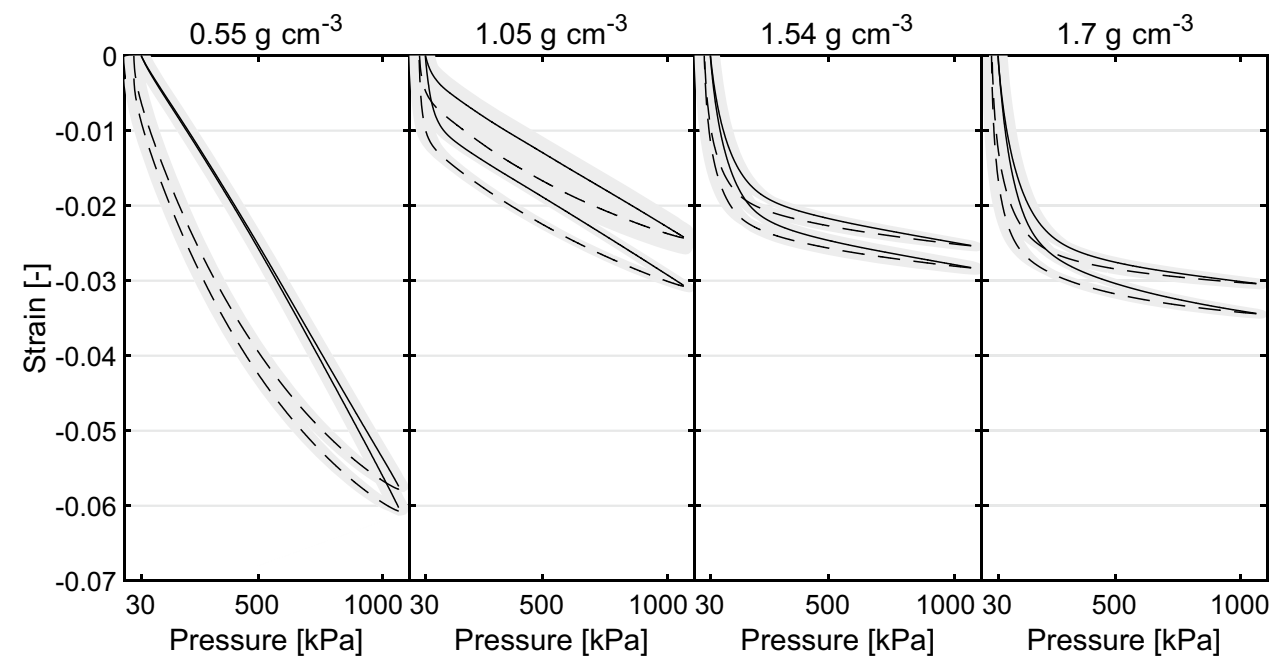

non-linear. For the higher densities the compression becomes progressively more non-linear and the curves flatten at higher pressures. The decompression is nonlinear for all the densities. The strain during compression can be evaluated using the surface fit:

$$
\begin{gathered}
S_{t h}=\left(0.0026-0.014 d+0.0166 d^{2}\right)\left(1-e^{-(p-30) 0.03 d^{-1.6}}\right) \\
+\left(0.00012-0.000147 d+4.8 \cdot 10^{-5} d^{2}\right)(p-30) \\
d \in[0.5,1.7] \mathrm{g} \mathrm{cm}^{-3}, p \in[30,1060] \mathrm{kPa},
\end{gathered}
$$

where $d$ is density in $\mathrm{g} \mathrm{cm}^{-3}$ and $p$ is pressure in $\mathrm{kPa}$; the fit predicts the data with maximum error of 0.004. The reference thickness for the strain calculation was taken at 30 $\mathrm{kPa}$ due to the noise and uncertainty at very low pressures; as a result, the reported stress-strain data could not be provided for the interval from 0 to $30 \mathrm{kPa}$.

The strain at maximum pressure, which quantifies the overall stiffness of the sheet, does not show a monotonically increasing or decreasing dependence on the density. It is the highest for the lowest density sample (6\%) but then drops and remains in the range of $2-3.5 \%$ for all remaining densities. The value of $11 \%$ at $0.81 \mathrm{MPa}$ reported in [17] is higher than any strain measured in this work.

The stiffness at any given pressure can be quantified by the tangent modulus. Figure 5 shows the average tangent moduli that were evaluated for the compression part of the stress-strain curves, i.e. the solid lines in Fig. 4. The linear shape of the stress-strain curve of the lowest density sample $\left(0.55 \mathrm{~g} \mathrm{~cm}^{-3}\right)$ translates to the constant value of the tangent modulus of approximately $20 \mathrm{MPa}$, which is comparable to the value of $10 \mathrm{MPa}$ for a $0.2 \mathrm{~g} \mathrm{~cm}^{-3}$ sheet in [18]. The $1.05 \mathrm{~g} \mathrm{~cm}^{-3}$ sheet shows a slight increase in the tangent modulus at pressures lower than $500 \mathrm{kPa}$ and then stabilizes at $50 \mathrm{MPa}$. The modulus of the remaining two

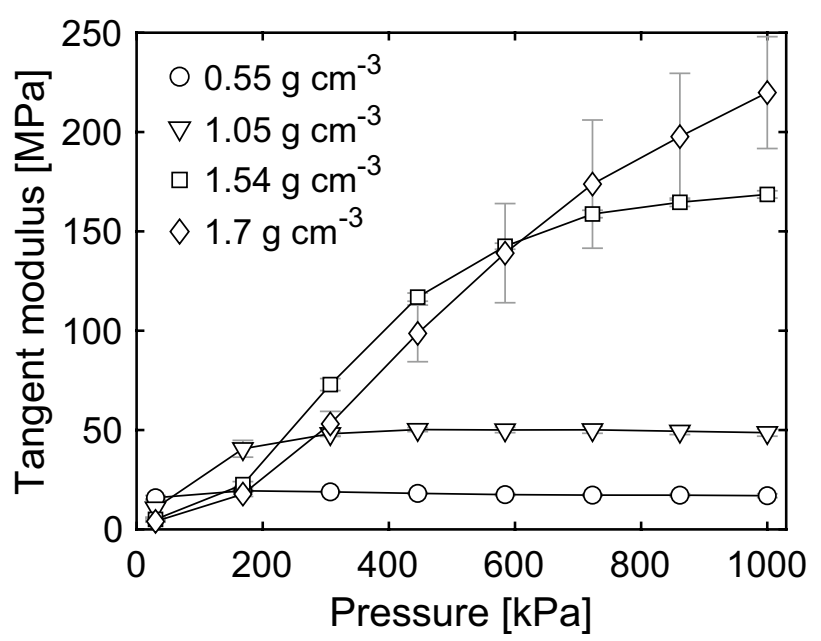

Fig. 5 Tangent compression modulus during the loading part of the compression cycle

densities $\left(1.54 \mathrm{~g} \mathrm{~cm}^{-3}\right.$ and $\left.1.7 \mathrm{~g} \mathrm{~cm}^{-3}\right)$ increases over the entire range of measured pressures and reaches $170 \mathrm{MPa}$ and $220 \mathrm{MPa}$, respectively. The increase follows an s-curve trend with the inflection point at approximately $500 \mathrm{kPa}$.

In comparison with the forming process, the viscous strain of finished NGS sheets is approximately two orders of magnitude smaller as shown in Fig. 6; however, a similar trend of decreasing magnitude with increasing density can be seen. To exclude the possibility of the viscous behavior being an artifact of the load cell, a control measurement with no sample between the compression platens was performed. The absolute dimension change during the constant pressure period of the control measurement was $0.3 \mu \mathrm{m}$, which is much smaller than lowest measured dimension change of $7.6 \mu \mathrm{m}$ for the $1.7 \mathrm{~g} \mathrm{~cm}^{-3}$ sample, and the viscous behavior is therefore be considered valid. 


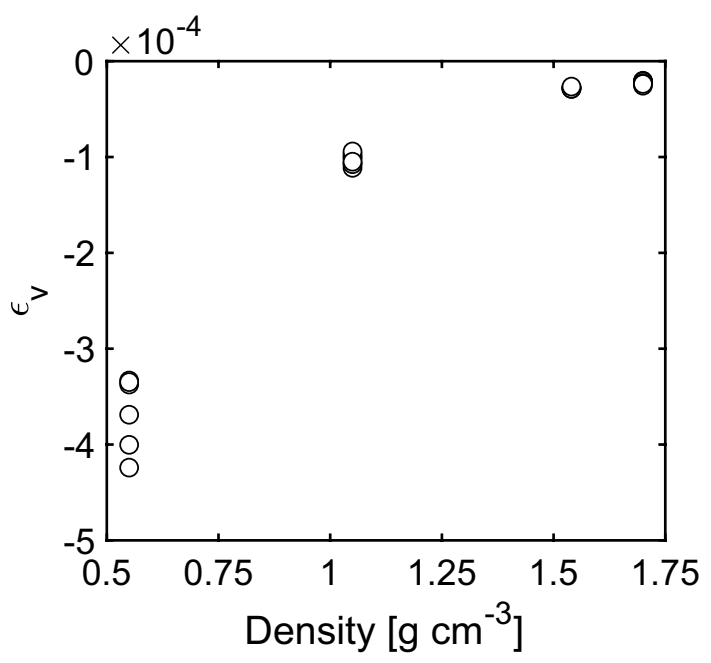

Fig. 6 The viscous strain during the $10 \mathrm{~s}$ period of constant pressure (1.06 $\mathrm{MPa})$ for each of the measured densities

\section{Discussion}

Compression of NGS increases its density but it is not possible to achieve the free-standing density equal to the theoretical density of a graphite crystal $\left(2.26 \mathrm{~g} \mathrm{~cm}^{-3}[21]\right)$. The reported values of the maximum achieved density vary from $1.73 \mathrm{~g} \mathrm{~cm}^{-3}$ at $p_{f}=31 \mathrm{MPa}$ [11] to $1.89 \mathrm{~g} \mathrm{~cm}^{-3}$ at $p_{f}=200 \mathrm{MPa}$ [13]. The drastic difference in the reported forming pressure is expected to be due to its unclear definition in the latter publication, which used a calendering process for manufacturing the sheets. The area used for calculating the pressure between two cylinders is ambiguous and was not reported. Moreover, the forming pressure of $200 \mathrm{MPa}$ is above the failure stress of $150 \mathrm{MPa}$ defined in [11].

In addition to the conclusion of Wei et al. [13] who observed that the maximum density is a function of the exfoliation volume, another trend can be observed when comparing the thickness of the sheets. While Dowell and Howard [11] reported that they tested stacks of sheets not less than $1.27 \mathrm{~mm}$ thick, the lowest thickness in [13] is $0.15 \mathrm{~mm}$. It is likely that a higher maximum density can be achieved by reducing the sheet thickness. The thinnest sheet in the present work was $0.84 \mathrm{~mm}$ thick, its density was $1.7 \mathrm{~g} \mathrm{~cm}^{-3}$, and it was formed by calendering under the $6.9 \mathrm{kN}$ compression force.

The viscous behavior of NGS observed in our measurements is in agreement with Chen and Chung [15] who reported a decreasing viscous effect with increasing density over the interval $0.0236-0.3503 \mathrm{~g} \mathrm{~cm}^{-3}$. As shown in Figs. 3 and 6, our data for higher densities $\left(0.3-1.7 \mathrm{~g} \mathrm{~cm}^{-3}\right)$ follows the same trend. Chen and Chung [15] attributed the viscous behavior to the sliding of graphite layers.
While this hypothesis is plausible, the viscous behavior can be also caused by the air trapped in the pores. The porosity of NGS ranges from 76 to $25 \%$ for $0.5 \mathrm{~g} \mathrm{~cm}^{-3}$ and $1.7 \mathrm{~g} \mathrm{~cm}^{-3}$, respectively, and the pores have been reported to be all open [11] or only $8 \%$ of them to be closed [14]. It is likely that upon compression, the air pressure in the pores increases and the air starts flowing out through the constrictions formed by the material structure allowing a gradual thickness reduction. Upon unloading, the stored elastic energy forces the sheet to expand, which lowers the pore pressure and air is drawn into the pores from the surroundings. To confirm or reject this assumption, the future measurements should be performed under vacuum.

The magnitude of the viscous behavior is low and likely negligible for the majority of the engineering applications. From the material characterization perspective, the viscous behavior can become significant when measuring properties that are highly sensitive to minute changes in the material structure. For example, the electrical resistance of NGS was found to follow the same exponential decay as the thickness and it should be addressed for highaccuracy measurements of electrical conductivity under compression. If a need to fully understand the viscous behavior of NGS arises, be it for engineering applications or to complete the scientific understanding of the phenomenon, an experimental setup capable of apply pressures of up to hundreds of mega pascals and measuring micrometer displacements is suggested.

Measurements of the compression modulus can be biased by the barreling effect [22]. The highly anisotropic structure of NGS was considered to be prone to this behavior as the low shear stiffness in the in-plane direction (perpendicular to the compression direction) can allow a high lateral displacement during the compression tests. The hypothesis was rejected based on the photographs of the stack of sixteen $1.54 \mathrm{~g} \mathrm{~cm}^{-3}$ sheets at $1030 \mathrm{kPa}$ in Fig. 7, which show no signs of lateral displacement.

\section{Conclusions}

The pressure required for forming NGS at a given freestanding density follows the proposed relationship $p_{f}=0.35 e^{2.6 d}$ where $d$ is the free-standing density in $\mathrm{g} \mathrm{cm}^{-3}$ and $p_{f}$ is the forming pressure in MPa. Re-loading sheet to the forming pressure causes a further increase of the free-standing density by up to $4 \%$ after 24 cycles. During the periods of constant forming pressure, NGS deforms viscously with up to $3 \%$ thickness reduction after $10 \mathrm{~s}$. The dwell time during the forming pressure should be considered when manufacturing NGS parts for which high accuracy in thickness and/or density is required. The prediction 


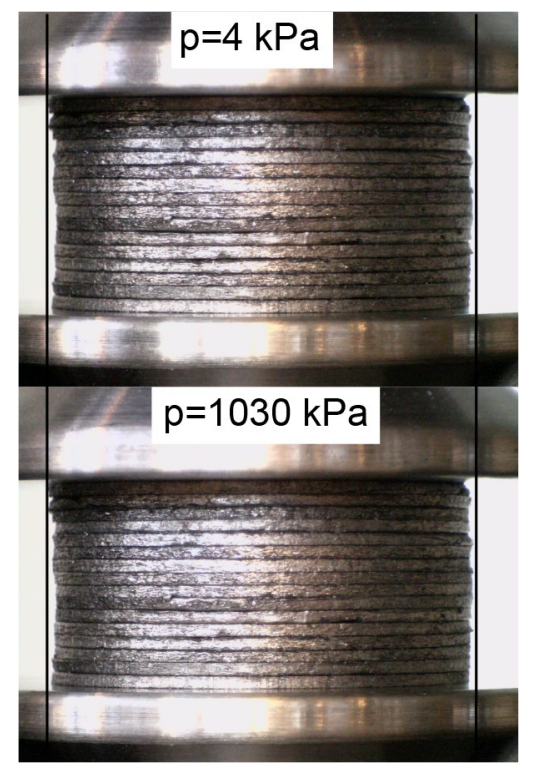

Fig. 7 A photograph of a stack of sixteen $1.54 \mathrm{~g} \mathrm{~cm}^{-3}$ sheets at 4 $\mathrm{kPa}$ (top) and $1030 \mathrm{kPa}$ (bottom). No lateral displacement was seen

of the maximum achievable free-standing density varies from 1.73 to $1.89 \mathrm{~g} \mathrm{~cm}^{-3}$.

The compression behavior of finished NGS sheets at densities ranging from 0.55 to $1.7 \mathrm{~g} \mathrm{~cm}^{-3}$ at pressures up to $1.06 \mathrm{MPa}$ shows high hysteresis that decreses with increasing density. The stress-strain behavior is linear only during the compression of the lowest-density sheet $\left(0.55 \mathrm{~g} \mathrm{~cm}^{-3}\right)$ and non-linear in all other cases; the nonlinearity increased with increasing density. A compact relationship for evaluating the strain at a given pressure and density is provided in Eq. 3. The strain at the maximum pressure $(1.06 \mathrm{MPa})$ is $6 \%$ for the $0.55 \mathrm{~g} \mathrm{~cm}^{-3}$ sheet and approximately $3 \%$ for the $1.05 \mathrm{~g} \mathrm{~cm}^{-3}$, $1.54 \mathrm{~g} \mathrm{~cm}^{-3}$, and $1.7 \mathrm{~g} \mathrm{~cm}^{-3}$ sheets. The tangent modulus of the $0.55 \mathrm{~g} \mathrm{~cm}^{-3}$ sheet is $20 \mathrm{MPa}$ and that of the $1.05 \mathrm{~g} \mathrm{~cm}^{-3}, 1.54 \mathrm{~g} \mathrm{~cm}^{-3}$, and $1.7 \mathrm{~g} \mathrm{~cm}^{-3}$ sheets increases from approximately $10 \mathrm{MPa}$ at $30 \mathrm{kPa}$ to $50 \mathrm{MPa}, 170$ $\mathrm{MPa}$, and $220 \mathrm{MPa}$ at $1 \mathrm{MPa}$, respectively. Small viscous deformations whose magnitude decreased with increasing density were detected during the periods of constant pressure. Lateral displacement of the compressed stacks (barreling) was not observed.

Acknowledgements The authors are thankful for financial support provided by the Natural Sciences and Engineering Research Council of Canada under the College-University Idea to Innovation Grant number 470927-14. The authors would also like to thank Dr. Kevin Oldknow for the discussion of the results and Masha Zalyvadna for the help with the data collection.

\section{Compliance with ethical standards}

Conflict of interest On behalf of all authors, the corresponding author states that there is no conflict of interest.

\section{References}

1. Middelman E, Kout W, Vogelaar B, Lenssen J, de Waal E (2003) Bipolar plates for PEM fuel cells. J Power Sources 118(1):44. https://doi.org/10.1016/S0378-7753(03)00070-3

2. Fu Y, Hou M, Liang D, Yan X, Fu Y, Shao Z, Hou Z, Ming P, Yi B (2008) The electrical resistance of flexible graphite as flowfield plate in proton exchange membrane fuel cells. Carbon 46(1):19. https://doi.org/10.1016/j.carbon.2007.10.020

3. Kopasz JP, Benjamin TG, Schenck D (2017) 2017 bipolar plate workshop summary report. Technical report. Argonne National Lab. (ANL), Argonne

4. Qian P, Zhang H, Chen J, Wen Y, Luo Q, Liu Z, You D, Yi B (2008) A novel electrode-bipolar plate assembly for vanadium redox flow battery applications. J Power Sources 175(1):613. https:// doi.org/10.1016/j.jpowsour.2007.09.006

5. Lourenssen K, Williams J, Ahmadpour F, Clemmer R, Tasnim $S$ (2019) Vanadium redox flow batteries: a comprehensive review. J Energy Storage 25:100844. https://doi.org/10.1016/j. est.2019.100844

6. Wang L, Metcalf S, Critoph R, Thorpe R, Tamainot-Telto Z (2011) Thermal conductivity and permeability of consolidated expanded natural graphite treated with sulphuric acid. Carbon 49(14):4812. https://doi.org/10.1016/j.carbo n.2011.06.093

7. Jamzad P, Kenna J, Bahrami M (2019) Development of novel plate heat exchanger using natural graphite sheet. Int J Heat Mass Transf 131:1205. https://doi.org/10.1016/j.ijheatmass transfer.2018.11.129

8. Norley J, Tzeng JJ, Getz G, Klug J, Fedor B (2001) The development of a natural graphite heat-spreader. In: Seventeenth annual IEEE semiconductor thermal measurement and management symposium (Cat. No. 01CH37189), pp 107-110. https ://doi.org/10.1109/STHERM.2001.915157

9. Cermak M, Bahrami M, Kenna J (2018) Natural graphite sheet heat sinks: a review of the material properties, benefits, and challenges. In: 2018 34th Thermal measurement, modeling management symposium (SEMI-THERM), pp 55-62. https:// doi.org/10.1109/SEMI-THERM.2018.8357353

10. Chung DDL (2016) A review of exfoliated graphite. J Mater Sci 51(1):554. https://doi.org/10.1007/s10853-015-9284-6

11. Dowell M, Howard R (1986) Tensile and compressive properties of flexible graphite foils. Carbon 24(3):311. https://doi. org/10.1016/0008-6223(86)90232-0

12. Wang L, Tamainot-Telto Z, Metcalf S, Critoph R, Wang R (2010) Anisotropic thermal conductivity and permeability of compacted expanded natural graphite. Appl Therm Eng 30(13):1805. https://doi.org/10.1016/j.applthermaleng.2010.04.014

13. Wei XH, Liu L, Zhang JX, Shi JL, Guo QG (2010) Mechanical, electrical, thermal performances and structure characteristics of flexible graphite sheets. J Mater Sci 45(9):2449. https://doi. org/10.1007/s10853-010-4216-y

14. Toda H, Tsubone K, Shimizu K, Uesugi K, Takeuchi A, Suzuki Y, Nakazawa M, Aoki Y, Kobayashi M (2013) Compression and recovery micro-mechanisms in flexible graphite. Carbon 59:184. https://doi.org/10.1016/j.carbon.2013.03.008 
15. Chen PH, Chung D (2013) Viscoelastic behavior of the cell wall of exfoliated graphite. Carbon 61:305. https://doi. org/10.1016/j.carbon.2013.05.009

16. Lai YH, Miller D, Ji C, Trabold T (2004) In: International conference on fuel cell science, engineering and technology, vol 2, pp 567-571. https://doi.org/10.1115/FUELCELL2004-2522

17. Luo X, Chung D (2001) Flexible graphite under repeated compression studied by electrical resistance measurements. Carbon 39(7):985. https://doi.org/10.1016/S0008-6223(00)00213-X

18. Afanasov IM, Savchenko DV, lonov SG, Rusakov DA, Seleznev AN, Avdeev VV (2009) Thermal conductivity and mechanical properties of expanded graphite. Inorg Mater 45(5):486. https ://doi.org/10.1134/S0020168509050057

19. Cermak M (2020) Natural graphite sheet heat sinks for power electronics. Ph.D. thesis, Simon Fraser University. (in preparation)

20. Cermak M, Bahrami M (2019) Compression behavior of natural graphite sheet - dataset. https://doi.org/10.20383/101.0207
21. Pierson HO (1993) In: Pierson HO (ed) Handbook of carbon, graphite, diamonds and fullerenes. William Andrew Publishing, Oxford, pp 43-69. https://doi.org/10.1016/B978-0-8155-13391.50008-6

22. Wei X, Chau K (2009) Finite and transversely isotropic elastic cylinders under compression with end constraint induced by friction. Int J Solids Struct 46(9):1953. https://doi.org/10.1016/j. ijsolstr.2009.01.007

Publisher's Note Springer Nature remains neutral with regard to jurisdictional claims in published maps and institutional affiliations. 